\title{
Social grooming in the common vampire bat, Desmodus rotundus
}

\author{
GERALD S. WILKINSON* \\ Institute for Behavioral Genetics, Campus Box 447, University of Colorado, Boulder, CO 80309, U.S.A.
}

\begin{abstract}
Grooming patterns among 65 common vampire bats in hollow tree day roosts were studied by behavioural sampling techniques during a 15-month period. Self-grooming occurred more than social grooming in response to ectoparasites since the proportion of time spent self-grooming and the amount of ectoparasite infestation covaried positively among tree roosts, while the time spent grooming others was independent of roost and ectoparasite level. Rates of social grooming were not independent of the sex of participants due to infrequent social grooming by adult males. Two variables, the level of relatedness and a measure of roosting association, which previously were shown to predict food sharing by regurgitation, correlated positively with the rate of social grooming. Since social grooming occurred more often than expected before a regurgitation and correlated with regurgitation frequency, it is suggested that this behaviour facilitates identification of food sharing partners by enabling a grooming bat to monitor other animals' potential for giving or receiving blood.
\end{abstract}

The functional significance of social grooming (licking, nibbling or picking at the fur of a conspecific) has yet to be unequivocally demonstrated in any species. If one assumes that social grooming costs a donor time that could have been allocated to self-maintenance or feeding but benefits a recipient either by removing ectoparasites (Freeland 1976), by helping to heal wounds (Simonds 1965), or by increasing the likelihood of support in an aggressive dispute (Seyfarth 1977, 1980, 1983; de Waal 1982), then either kin selection (Kurland 1977; Silk 1982) or reciprocity (Seyfarth \& Cheney 1984) must be invoked to explain the occurrence of this behaviour. However, Dunbar \& Sharman (1984) reviewed 40 baboon studies which measured the amount of time spent feeding, resting and social grooming and failed to find the expected negative relationship between time spent feeding and time spent social grooming. Instead, they discovered that the time allotted to social grooming was conserved. During periods of food shortage, resting time decreased to permit extended feeding periods. Consequently, at present there is no evidence that social grooming costs a donor by decreasing its reproductive success or survival.

Furthermore, although some primates groom conspecifics in locations that are hard to reach (Hutchins \& Barash 1976) and around recent wounds (Simonds 1965), there is little evidence to demonstrate that social grooming directly benefits a recipient by enhancing its survival or reproduc-

* Present address: Department of Zoology, University of Maryland, College Park, Maryland 20742, U.S.A. tion. Grooming might indirectly affect an animal's fitness, however, by influencing a partner's behaviour in future, more costly, situations. For example, Seyfarth (1977) has suggested that one female may groom a higher-ranking female to gain support from her in a subsequent aggressive alliance. If females form a linear dominance hierarchy with relatives in adjacent ranks and all of the females attempt to groom higher-ranking animals, then high-ranking females and close relatives will be groomed most often (Seyfarth 1977). This interpretation is supported by observations of kin-biased grooming distributions in several primate species (Seyfarth 1980, 1983). In a recent study, however, Seyfarth \& Cheney (1984) present results from a playback experiment on vervet monkeys which suggest that monkey $A$ will support an unrelated animal $\mathbf{B}$ in an aggressive interaction if $\mathbf{B}$ recently groomed A. This apparent reciprocal altruism did not occur among closely related monkeys. Of course, such an explanation does not preclude the operation of kin selection since aggressive alliances sometimes form more frequently among kin (Silk 1982) and can be independent of dominance relations (Dunbar 1980).

This brief review of primate grooming studies suggests that social grooming may serve purposes other than ectoparasite control in species with complex social behaviour. Unfortunately, very few non-primate grooming studies have been reported for comparison. Here, therefore, I present data on the frequency and distribution of social grooming in the vampire bat, Desmodus rotundus. This ani- 
mal is particularly appropriate for this analysis because females are known to exchange blood reciprocally by regurgitation with other females and young (Wilkinson 1984). At a study site in Costa Rica, three groups of 8-12 adult females share a common set of diurnal roosting trees and maintain exclusive foraging areas with respect to adjacent groups (Wilkinson 1985a). Long-term associations, as indicated by roosting in the same tree, exist between some pairs of females and significantly predict the likelihood of blood sharing (Wilkinson 1984). Although dominance hierarchies derived from confrontations over food have been described among captive $D$. rotundus (Schmidt \& van de Flierdt 1973), there is no evidence that such relations are important for wild bats. Due to occasional immigration of females, relatedness between females within groups varies between 0.5 and 0 with a mean relatedness estimated to be between 0.02 and 0.11 (Wilkinson $1985 \mathrm{~b}$ ). The level of relatedness between two bats is an independent significant predictor of the probability of regurgitation (Wilkinson 1984).

In opposition to this group-living benefit of reciprocally exchanging food is the apparent cost of harbouring more ectoparasites. The density of a streblid bat fly, Trichobius sp., and a mite, Macronyssiudes kochi, correlate positively with roosting group size (Wilkinson 1985a; Higgins \& Wilkinson, unpublished data). Therefore, in this paper I first consider whether oral manipulation of the fur (grooming) either by self or by another bat functions to remove or control these ectoparasites. I then examine the distribution both of directional and mutual social grooming with respect to age, sex, relatedness and association to suggest an alternative function for social grooming. Finally, I examine the relationship between social grooming and the occurrence of blood regurgitation.

\section{METHODS}

\section{Study Site and Time}

Observations were conducted on $D$. rotundus in northwestern Costa Rica at Hacienda La Pacifica from June to December 1980 and July to March 1981-1982. All adults and most juvenile bats which roosted in one of 14 hollow trees in the study area could be unambiguously identified after being marked with two or three coloured plastic reflecting bands and a numbered metal band on opposite forearms (see Wilkinson 1985a for capture details).
Genetic relatedness was determined from matrilineal pedigrees for one of the female groups (the upriver one) and confirmed with analyses of electrophoretic data (Wilkinson 1985b). A few of the pairwise values for relatedness in this study are different from those used in earlier reports (Wilkinson $1984,1985 \mathrm{a}, \mathrm{b})$ because here I employed Thompson's (1976) technique to find the pathways of maximum likelihood which connect females born prior to the study. This method provides the most parsimonious estimates of relatedness but does not change any of the qualitative conclusions presented previously (Wilkinson 1984, 1985a,b).

All 14 roost trees were examined for marked bats on 1 day each week from July 1981 until March 1982. I used the resulting 70 censuses to calculate a measure of association which estimates the expected number of times two bats should have been seen together if they visited roosts randomly in proportion to the number of times they were each observed in a tree. A significant value of this chi-squared statistic,

$$
\chi^{2}=\frac{\left(N_{i j}-\sum_{k=1}^{14} P_{i, k} P_{j, k} T\right)^{2}}{\sum_{k=1}^{14} P_{i, k} P_{j, k} T}
$$

where $T$ is the smaller of the two $N \mathrm{~s}$ and $P_{i, k}$ is the proportion of observations that bat $i$ spent in tree $k$, indicates that the two bats are found together more often than one would expect given any preference for a particular tree (Wilkinson 1985a).

\section{Observation Techniques}

My assistants and I spent over $400 \mathrm{~h}$ within two roost trees collecting ad libitum behavioural data (Altmann 1974) on 29 bats in the upriver group during 1981 and 1982 (cf. Wilkinson 1985a for methodology). During ad libitum observations we recorded all occurrences of social grooming bouts and scanned the tree every $10 \mathrm{~min}$ to identify all of the bats in view. A bout was defined as a grooming session which lasted at least $30 \mathrm{~s}$. If one bat groomed another, the direction of the interaction was noted; simultaneous grooming by two bats was classified separately as mutual grooming. I calculated the amount of time each pair of bats could have been seen during an observation period from the 10-min scans. The resulting time for each pair was then used to estimate the rate at which social 
grooming bouts occurred. All possible pairs of bats from the upriver group which had been observed together for at least $120 \mathrm{~min}$ were used to analyse directional and mutual grooming even if no grooming had been observed. Consequently, there were twice as many directional as mutual grooming bouts because each bat in a directional grooming pair could be both a donor and recipient.

Focal animal sampling (Altmann 1974) was conducted during the ad libitum observations by recording the behaviour of an individual every $10 \mathrm{~s}$ for 100 intervals $(16.7 \mathrm{~min})$. This was the shortest interval which permitted scan sample recording. We identified 20 mutually exclusive behaviours which could be recorded on an interval; however, most of these behaviours occurred infrequently. In this report only directional and mutual social grooming, self-grooming, any movement not performed in a social context such as crawling or flying, and inactivity (either hanging asleep or propped in an alert, but motionless position) are analysed. All other behaviours are lumped into one category. During 1-6-h observation periods on the upriver group, bats present in a tree on that day were sampled at random. We attempted to obtain an equal number of samples from each individual for each of three daytime observation periods (0500-0900, 0900-1300 and 1300-1700 hours) to control for potential diurnal variation in activity; subsequent analysis of variance indicated no significant effect of the observation period on behaviour proportions. Between July 1980 and March 1982 we compiled 466 focal animal samples on a total of 38 individuals from the upriver group and 290 samples on 27 bats from the downriver group. Mean behaviour proportions over a 6-month period were calculated for each bat. Only bats over 1 month of age with three or more focal animal samples during 6 months were included in the analysis described below. For this analysis, age changed in half-year increments.

\section{Statistical Analyses}

Neither the grooming rates calculated from the ad libitum data nor the proportion of time spent grooming obtained from the focal animal sample data follow a normal distribution. Furthermore, each behaviour proportion from a focal animal sample is not independent of other behaviour proportions from that sample since proportions must sum to 1 . To overcome these assumption violations and permit parametric analysis I transformed the data. To normalize the ad libitum data I raised directional and mutual grooming rate to the 0.3 power because this transformation proved more effective than the square root, often recommended for normalizing rare event data (Snedechor \& Cochran 1980), at reducing both skew and kurtosis to values not significantly greater than zero. To normalize the focal animal sample data and remove the problem of independence created by proportional data, I applied the additive logistic transformation (Aitchison 1982). This transformation converts $n+1$ categories of behaviour $x_{i}$ to $n$ new variables, $y_{i}$, where $y_{i}=\ln \left(x_{i} / x_{n+1}\right)$. Aitchison (1982) shows that this new variable set contains all of the information of the old and that each new variable is approximately normally distributed and compositionally independent of all other $y_{i}$. Each behaviour category was divided by the proportion of time each bat spent at rest, thereby allowing interpretation of the new variables as, for example, proportion of time spent grooming relative to time spent resting.

Analyses of covariance were performed on all data sets with the SPSSX statistical package (SPSS 1983) by entering main effects first, followed by covariates, followed by interactions. Since the direction of the behaviour was not relevant for the mutual grooming ad libitum data, the three possible sex dyads and three age combinations (less than or equal to 1 year: less than or equal to 1 year and greater than 1 year: greater than 1 year) were coded as two categorical variables, each with three values.

\section{RESULTS}

Four results suggest that self-grooming serves a different function than either directional or mutual grooming and most probably acts to control ectoparasites. First, self-grooming occurred almost ten times as often (mean proportion $=0.24$, $\mathrm{SD}=0 \cdot 259, N=756$ ) as either directional grooming (mean proportion $=0.022, \mathrm{SD}=0.078, N=756$ ) or mutual grooming (mean proportion $=0.028$, $\mathrm{SD}=0.092, N=756$ ) averaged over all sex and age classes (Fig. 1). Second, the rank correlation between self-grooming and social grooming (the sum of directional and mutual grooming) was not significant $\left(r_{\mathrm{s}}=0 \cdot 19, N=65\right)$ using 6 -month grooming averages for each individual. Third, the 

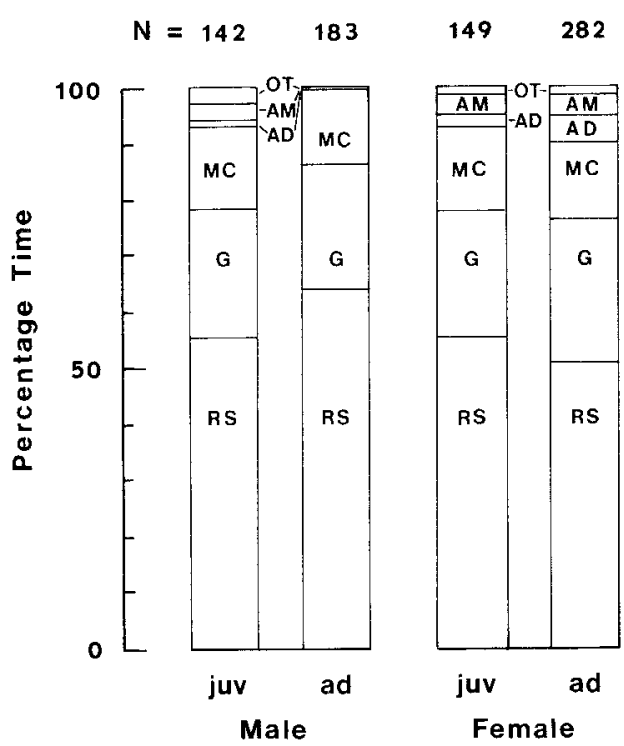

Figure 1. Percentage time spent either resting (RS), selfgrooming (G), moving (MC), grooming others (AD), mutually grooming (AM), or performing some other behaviour (OT) for juvenile (less than 12 months of age) and adult bats of each sex. Number of focal animal samples used is indicated above each bar.

proportion of time spent self-grooming relative to resting was not independent of roost tree while the relative proportion of time spent social grooming was independent of roost but was affected significantly by the sex of the grooming partner (Table I). These results suggest an ectoparasite removal

Table I. Analyses of covariance for log proportions of time spent grooming $(G)$ and social grooming (A) relative to resting $(R)$ from focal animal sample data

\begin{tabular}{|c|c|c|c|}
\hline \multirow[b]{3}{*}{ Source of variation } & \multirow[b]{3}{*}{$d f$} & \multicolumn{2}{|c|}{ Behaviour category } \\
\hline & & $\ln (G / R)$ & $\ln (\mathbf{A} / \mathbf{R})$ \\
\hline & & \multicolumn{2}{|c|}{$F$-ratios } \\
\hline Main effects & 3 & $4.498^{*}$ & $21 \cdot 230^{* *}$ \\
\hline Sex & 1 & $2 \cdot 638$ & $52 \cdot 222^{* *}$ \\
\hline Tree & 2 & $5 \cdot 092^{*}$ & 1.478 \\
\hline Covariate age & 1 & $3 \cdot 547$ & $1 \cdot 381$ \\
\hline Two-way interaction & 2 & 1.457 & $2 \cdot 876$ \\
\hline Explained & 6 & $3.326^{*}$ & $11 \cdot 804^{* *}$ \\
\hline Error & 58 & & \\
\hline$R^{2}$ & & 0.219 & 0.505 \\
\hline
\end{tabular}

${ }^{*} P<0.01 ; * * P<0.001$. function for self-grooming but not for social grooming because the number of bat flies Trichobius sp., and mites, Macronyssiudes kochi, found on netted bats differed significantly between bats which left different roost trees earlier in the night (Wilkinson 1985a; Higgins \& Wilkinson, unpublished data). Apparently, some trees were infected with ectoparasites more heavily than others. Furthermore, there were more ectoparasitic flies (mean proportion $=11.98, \mathrm{SD}=8.08, N=86$ ) on bats leaving the tree where self-grooming was most frequent (mean proportion $=0 \cdot 32, \mathrm{SD}=0 \cdot 28, N=53$ samples), during the 2-week periods that the bats were netted, than there were (mean proportion $=7 \cdot 31$, $\mathrm{SD}=7 \cdot 86, N=48$ ) on bats from the tree in which self-grooming was observed less frequently (mean proportion $=0 \cdot 28, \mathrm{SD}=0 \cdot 29, \quad N=166$ samples). And fourth, adult males, which were exposed to the same ectoparasites as females and young, spent about as much time self-grooming (mean proportion $=0 \cdot 22, \mathrm{SD}=0 \cdot 23, N=183$ samples) as other sex and age classes (mean proportion $=0 \cdot 25, \mathrm{SD}=0 \cdot 26$, $N=573$ samples) but almost never participated in social grooming (mean proportion $=0.0002$, $\mathrm{SD}=0.002, N=183$, Fig. 1).

To suggest a function for social grooming other than ectoparasite control, I examined other factors such as age, sex, relatedness and amount of time spent in the same roost as measured by the chisquared index of association, which might influence social grooming frequency. Using directional grooming bouts from the ad libitum observations, grooming rate showed significant dependence on both the level of relatedness and association (Table II) with significant interactions between age and sex of the donor and age and sex of the recipient. After excluding the 14 motherdependent-offspring pairs, the significant interactions disappeared (Table II) apparently because mothers groomed their offspring more frequently than other adult females groomed juveniles (Fig. 2). Since grooming rate correlated positively with both association $\left(r_{\mathrm{s}}=0 \cdot 18, P<0 \cdot 001, N=584\right)$ and relatedness $\left(r_{\mathrm{s}}=0.42, P<0.001\right)$, these results indicate that females and juveniles groom both close relatives and frequent roostmates more often than expected either by chance or by the correlation which existed between relatedness and association $\left(r_{\mathrm{s}}=0.28, P<0 \cdot 001\right)$. Unrelated individuals, however, showed no correlation between directional grooming rate and association $\left(r_{\mathrm{s}}=0.03, P=0.33\right.$, $N=244$ ). 
Table II. Analyses of covariance for directional grooming rate $\dagger$ using all ad libitum sample data and excluding 14 motheroffspring pairs

\begin{tabular}{|c|c|c|c|c|}
\hline \multirow[b]{3}{*}{ Source of variation } & \multicolumn{4}{|c|}{ Animals in analysis } \\
\hline & \multicolumn{2}{|r|}{ All } & \multicolumn{2}{|c|}{$\begin{array}{l}\text { No mothers } \\
\text { and young }\end{array}$} \\
\hline & $d f$ & $F$-ratio & $d f$ & $F$-ratio \\
\hline Main effects & 4 & 0.607 & 4 & 0.909 \\
\hline Age of donor & 1 & $1 \cdot 548$ & 1 & 0.089 \\
\hline Age of recipient & 1 & 0.602 & 1 & 0.817 \\
\hline Sex of donor & 1 & 0.089 & 1 & 0.813 \\
\hline Sex of recipient & 1 & $0 \cdot 344$ & 1 & 0.342 \\
\hline Covariates & 2 & $73 \cdot 327 * *$ & 2 & $73 \cdot 842^{* *}$ \\
\hline Relatedness & 1 & $110 \cdot 340^{* *}$ & 1 & $112-033^{* *}$ \\
\hline Association index & 1 & $17 \cdot 699 * *$ & 1 & $5 \cdot 237^{*}$ \\
\hline Two-way interactions & 6 & $2 \cdot 066^{*}$ & 6 & $1 \cdot 306$ \\
\hline Age donor $\times$ age recipient & 1 & $0 \cdot 185$ & 1 & 1.441 \\
\hline Age donor $\times$ sex donor & 1 & $6.339^{*}$ & 1 & $3 \cdot 259$ \\
\hline Age donor $\times$ sex recipient & 1 & 0.460 & 1 & $0 \cdot 173$ \\
\hline Age recipient $\times$ sex donor & 1 & $0-073$ & 1 & 0.003 \\
\hline Age recipient $\times$ sex recipient & 1 & $4 \cdot 466^{*}$ & 1 & $2 \cdot 344$ \\
\hline Sex donor $\times$ sex recipient & 1 & $0-089$ & 1 & $0 \cdot 104$ \\
\hline Three-way interactions & 4 & $0 \cdot 370$ & 4 & $0 \cdot 277$ \\
\hline Explained & 16 & $10 \cdot 185^{* *}$ & 16 & $10 \cdot 016^{* *}$ \\
\hline Error & 567 & & 553 & \\
\hline$R^{2}$ & & $0 \cdot 204$ & & $0 \cdot 212$ \\
\hline
\end{tabular}

$\dagger$ Rate $=(\text { No. bouts/day })^{0.3}$

${ }^{*} P<0.056 ;{ }^{* *} P<0.001$.
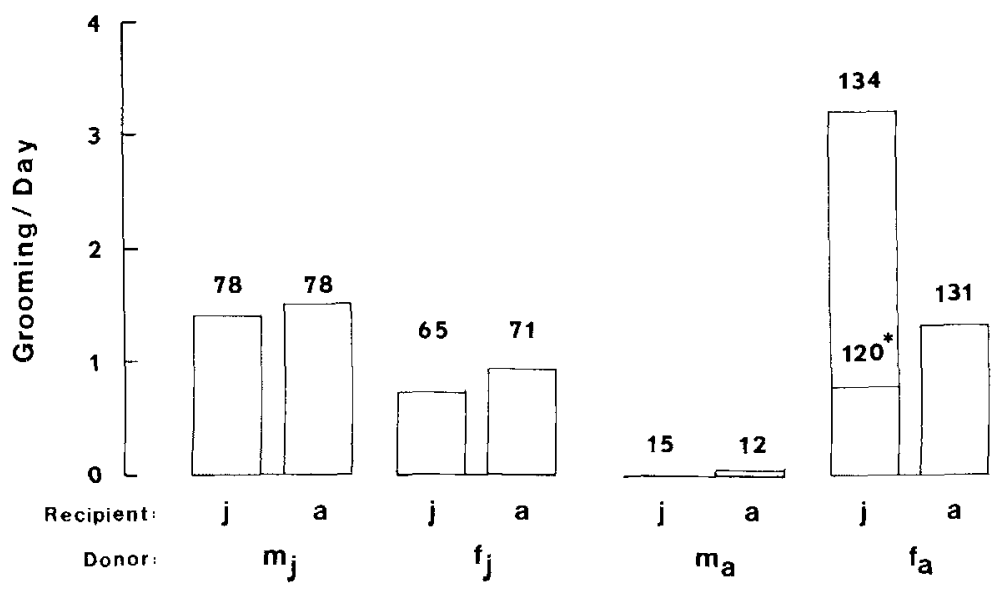

Age / Sex Class

Figure 2. Estimated mean number of directional grooming bouts observed per $24 \mathrm{~h}$ of ad libitum observations for pairs of juvenile ( $\mathrm{j}$, less than 12 months of age) and adult (a) male (m) and female (f) bats. Number of dyads is indicated above each bar. The asterisk refers to the mean grooming rate and sample size for adult female-juvenile dyads after motheroffspring pairs have been excluded. 
A similar pattern was revealed when the mutual grooming bouts from the ad libitum data were analysed. Mutual grooming rate was affected by age, sex and relatedness, but not association (Table III). These results were not influenced by lumping adult male-juvenile female pairs with adult femalejuvenile male pairs because when adult malejuvenile female pairs were removed from the data set, the significance patterns remained unchanged. However, when mothers and young were excluded, the effects due to age and sex increased and a significant interaction was revealed between them (Table III). This interaction was caused by the lack of adult male participation in mutual grooming and was revealed when the high rates of mutual grooming between mothers and offspring were removed (Fig. 3). Furthermore, by excluding mothers and offspring, the effect due to association increased five-fold and the effect due to relatedness decreased, also by a factor of five, while the amount of explained variation increased (Table III).

Association was not significant in the analysis of covariance using the entire mutual grooming data set because of the large correlation between relatedness and association $\left(r_{\mathrm{s}}=0.28, P<0 \cdot 001\right)$. Much of this correlation was due to high levels of associ- ation between mothers and their young. After these pairs were excluded, the correlation between association and relatedness fell $\left(r_{\mathrm{s}}=0.22\right.$, $P<0.001, N=278)$ and the correlation between grooming rate and association $\left(r_{\mathrm{s}}=0.30, P<0.001\right)$ became larger than that between grooming rate and relatedness $\left(r_{\mathrm{s}}=0.22, P<0.001\right)$. Furthermore, the correlation between association and mutual grooming rate among unrelated bats was highly significant $\left(r_{\mathrm{s}}=0.25, P=0.003, N=122\right)$. These results indicate that the amount of time spent together in the same diurnal roost tree as measured by the chi-squared index of association is as important as the level of relatedness in determining if two bats will groom socially.

The results on directional and mutual grooming rate suggest that the function of social grooming in the vampire bat may be related to the occurrence of food sharing by regurgitating blood since that behaviour also occurred more often than expected by chance, both between close relatives and frequent roostmates (Wilkinson 1984). I tested this possibility by counting the number of intervals in which directional or mutual grooming occurred between a donor and recipient 2 min before and 2 min after blood was regurgitated in the 14 cases of

Table III. Analyses of covariance for mutual grooming rate $\uparrow$ using all ad libitum sample data and excluding motheroffspring pairs

\begin{tabular}{|c|c|c|c|c|}
\hline \multirow[b]{3}{*}{ Source of variation } & \multicolumn{4}{|c|}{ Animals in analysis } \\
\hline & \multicolumn{2}{|r|}{ All } & \multicolumn{2}{|c|}{$\begin{array}{l}\text { No mothers } \\
\text { and young }\end{array}$} \\
\hline & $d f$ & $F$-ratio & $d f$ & $F$-ratio \\
\hline Main effects & 4 & $8 \cdot 357 * * *$ & 4 & $11 \cdot 829 * * *$ \\
\hline Age & 2 & $5 \cdot 496 * *$ & 2 & $10 \cdot 112^{* * *}$ \\
\hline Sex & 2 & $4 \cdot 179^{*}$ & 2 & $5 \cdot 106^{* *}$ \\
\hline Covariates & 2 & $41 \cdot 666^{* * *}$ & 2 & $14 \cdot 667^{* * *}$ \\
\hline Relatedness & 1 & $67 \cdot 803^{* * *}$ & 1 & $14.926 * * *$ \\
\hline Association index & 1 & $1 \cdot 246$ & 1 & $5 \cdot 525^{*}$ \\
\hline Two-way interaction & 2 & $2 \cdot 394$ & 2 & $2-836^{*}$ \\
\hline Explained & 9 & $13 \cdot 772^{* * *}$ & 9 & $9 \cdot 462^{* * *}$ \\
\hline Error & 282 & & 268 & \\
\hline$R^{2}$ & & $0 \cdot 218$ & & 288 \\
\hline
\end{tabular}




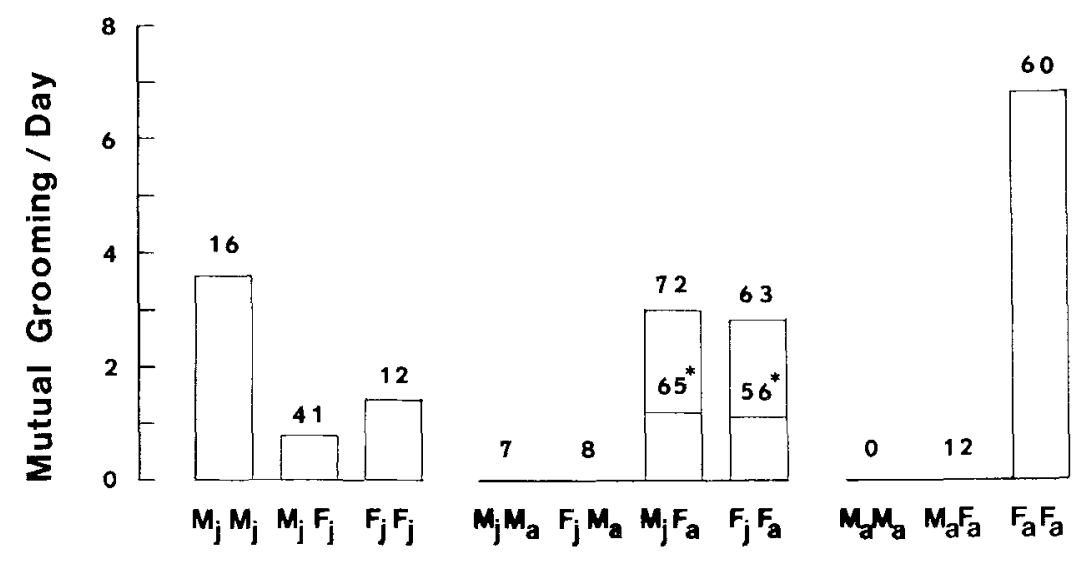

\section{Age/Sex Class}

Figure 3. Estimated mean number of mutual grooming bouts observed per $24 \mathrm{~h}$ of ad libitum observations for juvenile (j) and adult (a) male (M) and female (F) bats. Number of dyads in the group is indicated above each bar. The asterisk refers to the mean rate and sample size for adult female-juvenile pairs after mother-offspring pairs have been excluded.

food sharing witnessed while the donor was being observed as a focal animal. These counts were compared to the number of intervals which should contain directional and mutual grooming if social grooming occurred independently of food sharing at the average rate observed for the donor or recipient. In 12 of the 14 comparisons, a donor directionally or mutually groomed a recipient for more intervals than expected $(T=11, P<0.005$, Wilcoxon signed-ranks test) 2 min before a regurgitation but not more than expected 2 min after a regurgitation ( $T=43, P>0 \cdot 05$, Wilcoxon signedranks test). Although 11 of these regurgitations occurred between a mother and her young, two were between related adult females and one was between an adult female and an unrelated juvenile female. In all three non-mother-offspring cases, the expected number of intervals was lower than the observed before a regurgitation but greater than the observed after a regurgitation. Furthermore, eight of 14 ( $T=21, P=0.025$, Wilcoxon signedranks test) recipients directionally or mutually groomed a donor more times than expected $2 \mathrm{~min}$ before a regurgitation but also not more than expected $2 \mathrm{~min}$ after a regurgitation $(T=32$, $P \geq 0.05$, Wilxocon signed-ranks test).

These sequence analyses suggest that social grooming functions to convey information both to the donor and recipient before, but not after, a blood sharing event. This functional relationship is further supported by a significant correlation between the rate of regurgitation by members of the upriver group and the rate at which they groom other bats $\left(r_{\mathrm{s}}=0.404, N=584, P<0.001\right)$ even when mother-offspring pairs were excluded $\left(r_{\mathrm{s}}=0.254, N=570, P<0.001\right)$.

\section{DISCUSSION}

Although the analyses presented here do not exclude the possibility that social grooming may affect ectoparasite levels, they do indicate that social grooming must serve other functions and appears to be less important than self-grooming in the removal or control of ectoparasites. This interpretation is consistent with a previous analysis (Wilkinson 1985a) which failed to find a correlation between social grooming rate and individual ectoparasite counts. The distribution of both directional and mutual grooming is similar to that reported for most primate studies in that social grooming bouts occur more often than expected by chance between close relatives. In addition, when mother-offspring pairs are excluded, the amount of time spent together in the same day roost significantly covaries both with directional and mutual grooming rate. Inspection of the $F$-ratios in Tables II and III reveals that the relative degree of 
correlation between directional grooming rate and relatedness is substantially larger than that for association. One interpretation of this pattern is that directional grooming may serve a different function than mutual grooming. It must be noted, however, that the directional grooming data set consists of all possible combinations of pairs of bats. Consequently, the association and relatedness of each pair of bats enters into these analyses twice. Patterns of significance similar to those observed in the mutual grooming analysis of covariance emerge when the directional grooming analysis of covariance is performed on only those pairs which have non-zero directional grooming rates. In this analysis, the $F$-ratio for relatedness is only four times the $F$-ratio for association; a relationship almost identical to that observed for the mutual grooming analysis of covariance.

The grooming rate analyses were performed with and without mother-offspring pairs to permit comparison with the logistic regression analysis of regurgitation presented in Wilkinson (1984). In that study, regurgitation between mothers and their dependent offspring were excluded because they were considered to be cases of parental care. If, however, social grooming does not affect the ectoparasite level of juvenile bats (self-grooming begins at 1 month of age, prior to any of the observations used in the analyses presented here), then the high levels of directional and mutual grooming observed between mothers and their young deserve an explanation. One possibility is that mothers groom their offspring to facilitate recognition; potentially both between the mother and her young and vice versa. Although no scent glands have been described in this species, their olfactory thresholds to organic acids are equal to or better than some fruit bats (Schmidt 1975) and humans (Schmidt 1973). Thus, there is potential for olfactory marking by saliva and subsequent recognition. Furthermore, both infants and their mothers have faint contact calls which are sometimes given during social grooming (Schmidt 1972; Schmidt \& Manske 1973) and which show some variation between individuals (S. Park, personal communication). The exact function of this low frequency $(6-12 \mathrm{kHz})$ call is unknown, but social grooming undoubtedly facilitates maintenance of the proximity necessary to hear it.

Since social grooming correlates with regurgitation rate and occurs unusually often before a regurgitation, I suggest that this behaviour may be functionally related to food sharing. Social grooming could provide information both about the identity of individuals which roost together frequently and are therefore most likely to provide food during times of need in the future and about those individuals' recent feeding histories. Since these bats can ingest their body weight in blood (Wimsatt 1969) and hold much of this liquid in highly distensible stomachs, a groomer should be able to assess the amount of blood in a potential recipient's or donor's stomach by feeling the bulge in its abdomen. Although we did not quantify grooming locations during our observations, much of the grooming occurred underneath the wings near the stomach. This provides a convenient mechanism for detecting offspring that failed to obtain a sufficiently large blood meal. In addition, if these bats remember the animals to which they donated blood, as reciprocal exchanges among captive D. rotundus suggest (Wilkinson 1984), then individuals not participating in reciprocal blood donations within the group could be identified and punished. For a reciprocal exchange system to persist successfully, one predicts that non-reciprocators will be admonished or ostracized (Axelrod 1984). Female fights do occur frequently within a group, but since we were unable to monitor blood intake on a daily basis, we do not know if the attacked female was a potential cheater. Carefully designed experiments are needed to test these ideas and elucidate the sensory modalities used to discriminate between relatives and frequent roostmates.

Although the relationship between social grooming and food sharing in vampire bats appears unique, other bats may socially groom for similar reasons. Female greater spear-nosed bats, Phyllostomus hastatus, also groom each other and their young inside cave roosts (personal observation). This behaviour may facilitate recognition of group members since most females within a group are distantly related (McCracken \& Bradbury 1980) or provide information about the feeding status of young since these bats also regurgitate food to their offspring (personal observation). Another possible function of social grooming in these and other bats which feed on fruit, nectar and pollen is the acquisition of food. The head of a $P$. hastatus or $P$. discolor, another social grooming species (personal observation), is frequently covered in pollen which is groomed off and ingested. It should be realized, though, that not all group living bats groom 
socially. Carollia perspicillata and Artibeus jamaicensis are neotropical fruit eating bats in the same family as Phyllostomus and Desmodus for which conspecific grooming has never been observed, despite extensive observations (Wilkinson, in press). Although these two species form female groups, both the level of relatedness and the apparent compositional stability of the group are substantially less than either Phyllostomus species or D. rotundus (Wilkinson, in press). This information suggests that social grooming in some bats may entail a sufficient cost to preclude performance unless kin or potential reciprocators are involved. Russell (1983) has argued that social grooming between unrelated female coatis, Nasua narica, can only be explained by reciprocity. Further observation of social grooming among non-primate social mammals is needed to determine if reciprocity, kin selection or an alternative explanation such as that proposed in this paper can account for the occurrence of this conspicuous behaviour among many species.

\section{ACKNOWLEDGMENTS}

This research was supported by NSF grant DEB8001165 to J. Bradbury. During preparation of the manuscripts stipends were provided by NATO and NIMH postdoctoral fellowships. I thank M. Jones, T. Lamp and R. Weiss for assistance in the field, $R$. Stark for helping to enter data and $\mathrm{W}$. and $\mathrm{L}$. Hagenauer for generous hospitality and permission to study vampire bats at La Pacifica. Computer time was provided by the Psychology Department at the University of Colorado, Boulder.

\section{REFERENCES}

Aitchison, J. 1982. Statistical analysis of compositional data. Jl R. Statist. Soc. B, 44, 139-177.

Altmann, J. 1974. Observation study of behaviour: sampling methods. Behaviour, 49, 227-267.

Axelrod, R. 1984. The Evolution of Cooperation. New York: Basic Books.

Dunbar, R. I. M. 1980. Determinants and evolutionary consequences of dominance among female gelada baboons. Behav. Ecol. Sociobiol., 7, 253-265.

Dunbar, R. I. M. \& Sharman, M. 1984. Is social grooming altruistic? Z. Tierpsychol., 64, 163-173.

Freeland, W. R. 1976. Pathogens and the evolution of primate sociality. Biotropica, 8, 12-24.

Hutchins, M. \& Barash, D. P. 1976. Grooming in primates: implications for its utilitarian function. Primates, 17, 145-150.

Kurland, J. A. 1977. Kin Selection in the Japanese Monkey. Basel: Karger.

McCracken, G. F. \& Bradbury, J. W. 1980. Social organization and kinship in the polygynous bat Phyllostomus hastatus. Behav. Ecol. Sociobiol., 8, 11-34.

Russell, J. K. 1983. Altruism in coati bands; nepotism or reciprocity? In: Social Behavior of Female Vertebrates (Ed. by S. K. Wasser), pp. 263-290. New York: Academic Press.

Schmidt, U. 1972. Social calls of juvenile vampire bats (Desmodus rotundus) and their mothers. Bonn. zool. Beitr., 23, 310-316.

Schmidt, U. 1973. Olfactory threshold and odour discrimination of the vampire bat (Desmodus rotundus). Period. Biol., 75, 89-92.

Schmidt, U. 1975. Vergleichende Riechschwellenbestimmungen bei neotropischen Chiropteren (Desmodus rotundus, Artibeus literatus, Phyllostomus discolor). $Z$. Säugetierkd., 40, 269-298.

Schmidt, U. \& van de Flierdt, K. 1973. Innerartliche Aggression bei Vampirfledermäusen (Desmodus rotundus) am Futterplatz. Z. Tierpsychol., 32, 139-146.

Schmidt, U. \& Manske, U. 1973. Die Jugendentwicklung der Vampirfledermäuse (Desmodus rotundus). Z. Säugetierkd., 38, 14-33.

Seyfarth, R. M. 1977. A model of social grooming among adult female monkeys. $J$. theor. Biol, 65, 671-698.

Seyfarth, R. M. 1980. The distribution of grooming and related behaviours among adult female vervet monkeys. Anim. Behav., 28, 798-814.

Seyfarth, R. M. 1983. Grooming and social competition in primates. In: Primate Social Relationships, an Integrated Approach (Ed. by R. A. Hinde), pp. 182-190. Sunderland: Sinauer.

Seyfarth, R. M. \& Cheney, D. L. 1984. Grooming, alliances and reciprocal altruism in vervet monkeys. Nature, Lond., 308, 541-543.

Silk, J. B. 1982. Altruism among female Macaca radiata: explanations and analysis of patterns of grooming and coalition formation. Behaviour, 79, 162-188.

Simonds, P. E. 1965. The bonnet macacque in South India. In: Primate Behavior (Ed. by I. DeVore), pp. 175-196. New York: Holt, Rinehart \& Winston.

Snedecor, G. W. \& Cochran, W. G. 1980. Statistical Methods. 7th edn. Ames: Iowa State University Press.

SPSS. 1983. SPSSX User's Guide. New York: McGrawHill.

Thompson, E. A. 1976. Inference of genealogical structure. Soc. Sci. Inform., 15, 477-526.

de Waal, F. 1982. Chimpanzee Politics: Power and Sex Among Apes. London: Jonathan Cape.

Wilkinson, G. S. 1984. Reciprocal food sharing in vampire bats, Nature, Lond., 309, 181-184.

Wilkinson, G. S. 1985a. The social organization of the common vampire bat. I. Pattern and cause of association. Behav. Ecol. Sociobiol., 17, 111-121.

Wilkinson, G. S. 1985b. The social organization of the common vampire bat. II. Mating system, genetic structure, and relatedness. Behav. Ecol. Sociobiol., 17, 123-134.

Wilkinson, G. S. In press. Cooperation and altruism in 
bats. In: Recent Advances in the Study of Bats (Ed. by M. B. Fenton, P. A. Racey \& J. M. V. Rayner). Cambridge: Cambridge University Press.

Wimsatt, W. A. 1969. Transient behavior, nocturnal activity patterns, and feeding efficiency of vampire bats
(Desmodus rotundus) under natural conditions. $J$. Mammal., 50, 233-244.

(Received 16 November 1985; revised 2 December 1985; MS. number: A4580) 